\title{
Botox ForRhytides of the Forehead- A Case Report
}

\author{
Dr. Sonia Jindal \\ Professor And Head Of Department(Oral And Maxillofacial Surgery), Darshan Dental College And Hospital.
}

\begin{abstract}
Positive effects on mood have been observed in subjects who underwent treatment of fore head frownlines with botulinum toxin and, in an open case series, depression remitted or improved after such treatment. This study shows that treatment of the forehead region with botulinum toxin may shortly accomplish a strong and sustained alleviation of depression in patients, who did not improve sufficiently on previous medication. It supports the concept, that the facial musculature not only expresses, but also regulates mood states.
\end{abstract}

Keywords: Facial feedback, Emotional contagion, Major depression, Botulinum neurotoxin.

\section{Introduction}

Botox is a Botulinum Toxin derived from Clostridium botulinum. It prevents the release of the neurotransmitter acetylcholine from axon endings at the neuromuscular junction and thus causes flaccid paralysis. There are seven types of botulinum toxin, named A-G. In cosmetic applications, botulinum toxin is considered safe and effective for reduction of facial wrinkles, especially in the uppermost third of the face ${ }^{1}$. Injection of botulinum toxin into the muscles under facial wrinkles causes relaxation of those muscles, resulting in the smoothing of the overlying skin. Smoothing of wrinkles is usually visible three days after treatment and is maximally visible two weeks following injection. The treated muscles gradually regain function, and generally return to their former appearance three to four months after treatment. Muscles can be treated repeatedly to maintain the smoothed appearance ${ }^{2}$.

\section{Anatomy}

Contraction of the frontalis muscle elevates the brow and results in dynamic transverse foreheadrhytides. The frontalis is the principal elevator ofthe brow, originating in the galeaaponeuroticaand inserting into the subcutaneous tissues anddeep dermis of the skin overlying the superciliaryarch. Although commonly depicted as 2 distinctmuscle bellies, anatomic variation is common, with many showing significant medial overlappingand structural difference between the medial andlateralaspects. Theglabellar complex depresses the medial browand consists of the paired corrugator superciliimuscles and the central procerus muscle. The action of the medial orbicularis is also to depress thebrow, but its contribution is weak by comparison. The corrugators originate on the frontal bonemedially, where their fibers can interdigitatewiththose of the medial preorbital orbicularis oculi,and insert into the dermis of the forehead, justabove the eyebrow at the midpupillary line $e^{3}$. Theirprimary action is to medialize and depress themedial brow. Hyperactivity contributes to verticalglabellarrhytides. Theprocerus muscle is a vertically oriented,midline structure, originating from the soft tissuesoverlying the nasal bones and inserting into theskin of the lower central forehead, superior to thenasal root. Contraction of this muscle producestransverse horizontal rhytides at the nasal root ${ }^{4}$.

\section{Treatment Recommendations}

The goals of treating the forehead are to soften theappearance of dynamic rhytides without giving anunnatural, unexpressive appearance and avoidingiatrogenic brow ptosis. The efficacy and safety ofBTA in treating this area of the face have beenwell documented in the literature.

\section{Case Report}

Treatment of the forehead is highly variable because of the anatomic variability of the frontalis muscle and characteristics of each patient's animation patterns.Before injection, any brow asymmetry is noted and discussed with the patient, as this may only come to their attention after treatment. Patients are asked to forcefully elevate their brow to assess the strength of frontalis contraction and the location of dynamic rhytides. The frontalis is typically injected in 4 to 6 sites, with care taken to stay at least 1 to $2 \mathrm{~cm}$ above the supraorbital rim to avoid brow or eyelid ptosis. 


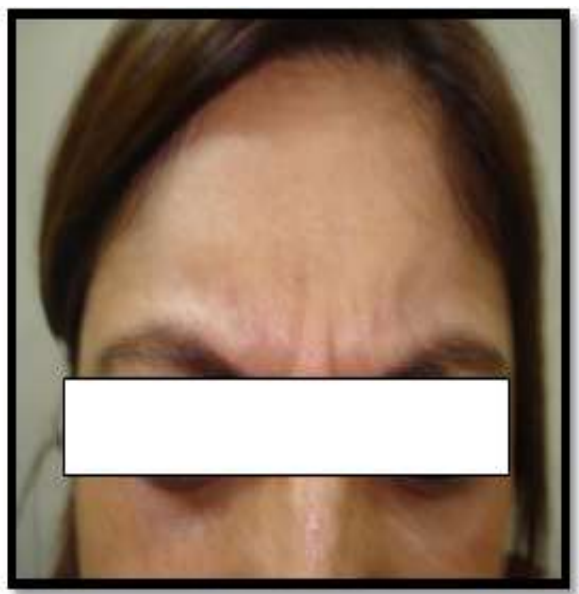

(a)

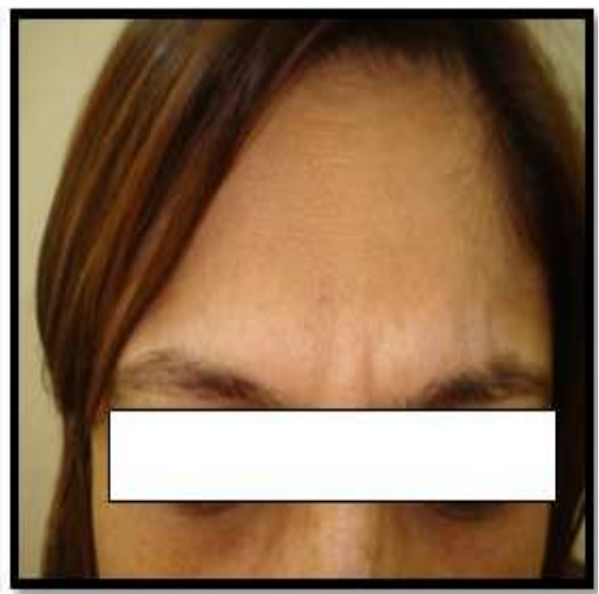

(b)

(Picture-1,(a) before (b) after treatment.)

Treatment of the forehead is highly variablebecause of the anatomic variability of the frontalismuscle and characteristics of each patient's animation patterns.Beforeinjection, any brow asymmetry is noted and discussed with the patient, as this may only cometo their attention after treatment. Patientsareasked to forcefully elevate their brow to assessthe strength of frontalis contraction and the location of dynamic rhytides. The frontalis is typicallyinjected in 4 to 6 sites, with care taken to stay atleast 1 to $2 \mathrm{~cm}$ above the supraorbital rim to avoidbrow or eyelid ptosis (Picture 1,2).

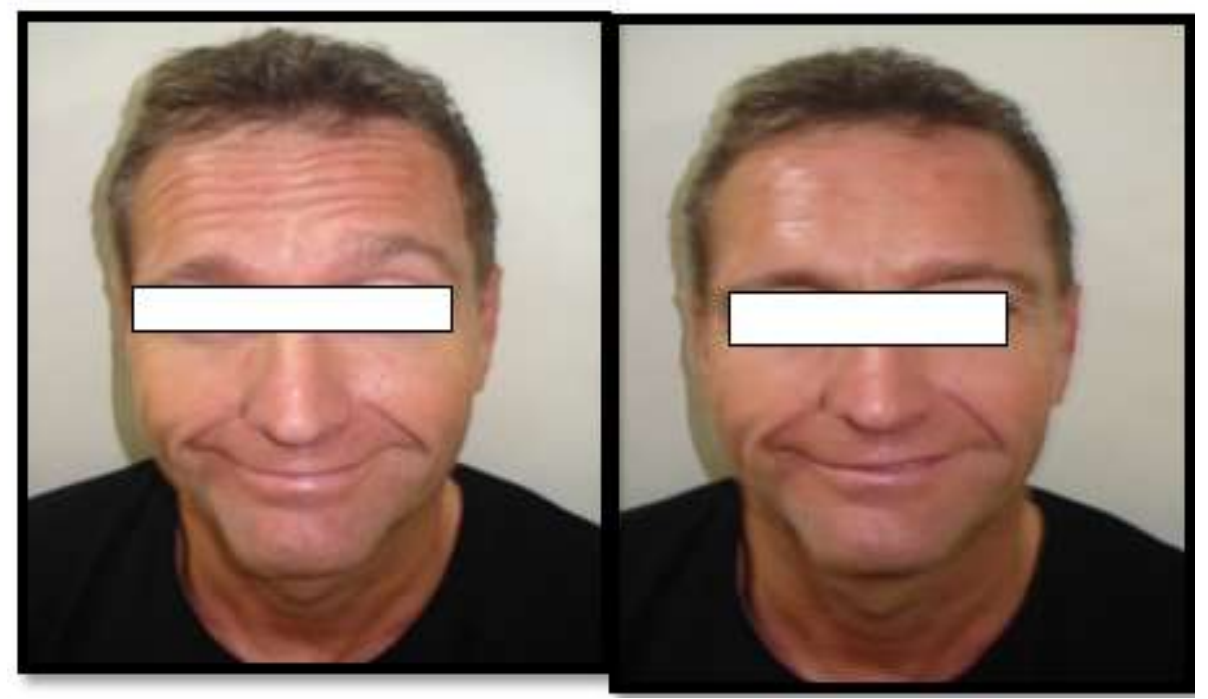

(a)

(b)

(Picture-2, (a) before (b) after treatment.)

The authors prefer to injecteach belly of the frontalis in a V-shaped pattern; however, this varies based on each patients' muscular patterns.Muscle size, strength, and location can be esti-mated by asking the patient to frown maximally.Any asymmetry in muscle strength or contractionshould be carefully evaluated before injection. The authors typically inject in a 5-point $\mathrm{V}$ pattern, with 2 injection sites in each corrugator and 1 inthe central procerus. Injections should bekept a minimum of $1 \mathrm{~cm}$ above the orbital rim toavoid diffusion into the levatorpalpebraesuperioris muscle, causing iatrogenic ptosis (Picture 3). The patientis asked to frown to confirm the location of eachmuscle belly just before injection. In patientswithmild muscle activity, 3 injection points may be .used instead

\section{Discussion}

In 1820, JustinusKerner, a small-town German medical officer and romantic poet, gave the first complete description of clinical botulism based on extensive clinical observations of so-called "sausage poisoning". Following experiments on animals and on himself, he concluded that the toxin acts by interrupting signal transmission in the somatic and autonomic motor systems, without affecting sensory signals or mental 
functions ${ }^{6}$. He observed that the toxin develops under anaerobic conditions, and can be lethal in minute doses. His prescience in suggesting that the toxin might be used therapeutically earned him recognition as the pioneer of modern botulinum toxin therapy. In 2002, following clinical trials, the FDA approved Botox Cosmetic, botulinumA toxin to temporarily improve the appearance of moderate-to-severe glabellar lines ${ }^{7}$.

The cosmetic effect of BTX-A on wrinkles was originally documented by a plastic surgeon from Sacramento, California, Richard Clark, and published in the journal Plastic and Reconstructive Surgery in $1989^{8}$. Canadian husband and wife ophthalmologist and dermatologist physicians, JD and JA Carruthers, were the first to publish a study on BTX-A for the treatment of glabellar frown lines in $1992^{9}$. After formal trials, on April 12, 2002, the FDA announced regulatory approval of botulinum toxin type A (Botox Cosmetic) to temporarily improve the appearance of moderate-to-severe frown lines between the eyebrows (glabellar lines). Subsequently, cosmetic use of botulinum toxin type A has become widespread. The results of Botox Cosmetic can last up to four months and may vary with each patient ${ }^{10}$.

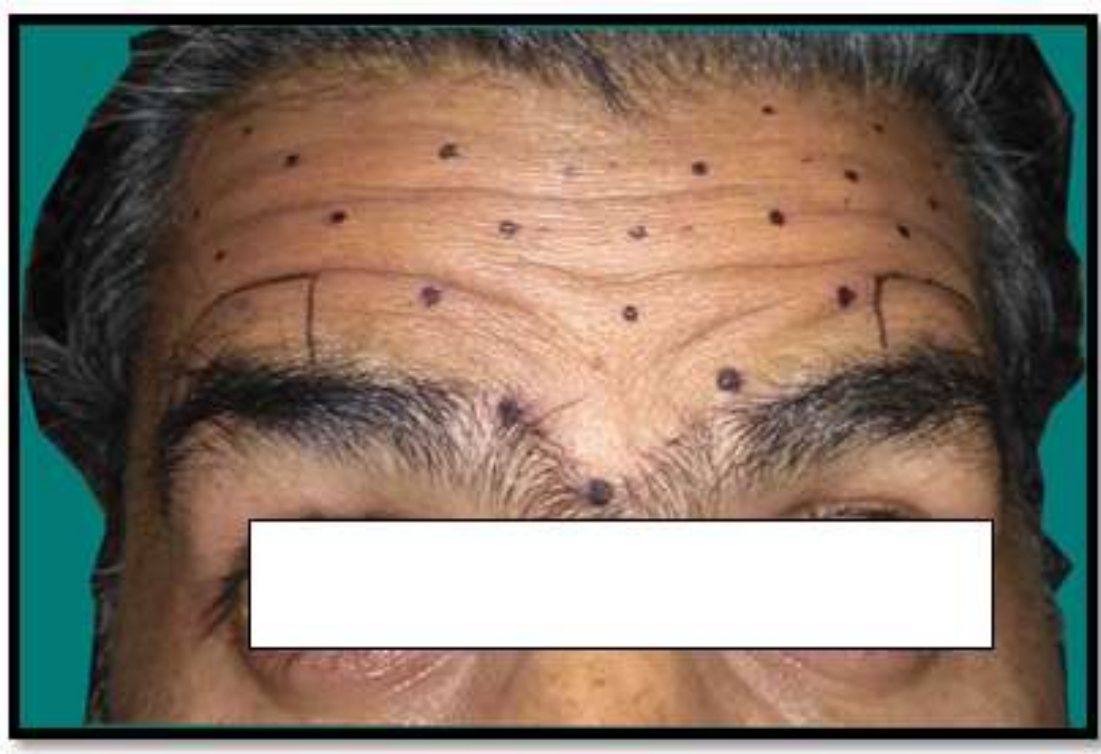

(Picture-3,Extended triangular pattern of injection.)

Botulinum toxin is synthesized as a $150-\mathrm{kDa}$ protein that undergoes posttranslational modification into a $100-\mathrm{kDa}$ heavy chain and a $50-\mathrm{kDa}$ light chain, linked by a disulfide bridge. The heavy chain binds to the presynaptic neurons at the neuromuscular junction and facilitates entry of the light chain into the cell cytoplasm ${ }^{12}$. There, each serotype's light chain targets a component of the soluble N-ethylmalei-mide-sensitive factor attachment protein receptor(SNARE) complex, which it cleaves to and thereby inactivates. The components of the SNARE complex are all essential for microvesicle fusion and release of stored neurotransmitter ${ }^{14}$. BTA targets synaptosomal-associated protein, $25 \mathrm{kDa}$ BTB target synaptobrevin, also known asvesicle-associated membrane proteinBy inhibiting the release of stored neurotransmitter at the neuromuscular junction,botulinumneurotoxins cause a flaccid paralysis of target muscles. Paralysis and a near-complete loss ofmotor end plate potentials occur within a few hours of botulinum neurotoxin injection; however,the clinical effect may not become evident for upto 1 week after administration.The latency toclinical effect may be caused by spontaneous,non vesicle-associated release of acetylcholineat the neuromuscular junction. The neuromuscular blockade from botulinum toxin administra-tion is irreversible. Axonal sprouting and the formation of new neuromuscular junctionsareresponsible for the dissipation of clinical effects over time ${ }^{17}$.

Currently, there are 4 commonly used preparations of botulinum toxin: onabotulinumtoxin (Botox; Botox Cosmetic, Allergan, Irvine, CA), abobotulinumtoxinA (Dysport; Ipsen, Ltd, Berkshire,UK), incobotulinumtoxinA (Xeomin; Merz Pharmaceuticals, Frankfurt, Germany), and rimabotulinumtoxinB (Myobloc; Solstice Neurosciences,San Francisco, CA) ${ }^{19}$.

\section{Conclusion}

The findings of this study support the use of BTA for the treatment of hyperkinetic lines of the face although further studies with more sample size are required. 


\section{References}

[1]. Klien AW. Dilution and storage of botulinumtoxin.Dermtol Surg. 1998;24:1179-1180. doi: 10.1016/S1076-0512(98)00178-2. [PubMed]

[2]. Carruthers JA, Lowe NJ, Menter A, Gibson J, Nordquist M, Mordaunt J, Wexler P, Eadie N. Double blind, placebo: controlled study of the safety and efficacy of botulinum toxin type A for patients with glabellar lines. PlastReconstr Surg. 2003;112:10891098. [PubMed]

[3]. Carruthers JA, Lowe NJ, Menter MA, Gibson J, Nordquist M, Mordaunt J, Wexler P, Eadie N. A multicenter, double blind, randomized placebo: controlled study of the efficacy and safety of botulinum toxin type A in the treatment glabellar lines. $\mathrm{J}$ Am AcadDermatol. 2002;46(6):840-849. doi: 10.1067/mjd.2002.121356. [PubMed]

[4]. Sommer B, Zschoke I, Bergfeld D, Sattler G, Augustin M. Satisfaction of patients after treatment with botulinum toxin for Dynamic facial lines. Dermatol Surg. 2003;29:456-460. doi: 10.1046/j.1524-4725.2003.29113.x. [PubMed]

[5]. Niamtu Joseph., III Botulinum toxin A: a review of 1,085 oral and maxillofacial patients treatments. J Oral Maxillofac Surg. 2003;61:317-324. doi: 10.1053/joms.2003.50069. [PubMed]

[6]. Niamtu J., III The use of botulinum toxin in cosmetic facial surgery. Oral MaxillofacSurgClin North America. 2000;12(4):595-612

[7]. Hankins CL, Strimling R, Rogers G. Botulinum A toxin for glabellar wrinkles: dose and response. Dermatol Surg. 1998;24:11811183. doi: 10.1016/S1076-0512(98)00179-4. [PubMed]

[8]. Benedtto AV. The cosmetic uses of botulinum toxin type A. Int J Dermatol. 1999;38:641-655. doi: 10.1046/j.13654362.1999.00722.x. [PubMed]

[9]. Caruthers J, Carruthers JA. Aesthetic botulinum toxin A in the mid and lower face and neck.Dermatol Surg. 2003;29:468-476. doi: 10.1046/j.1524-4725.2003.29115.x. [PubMed]

[10]. Flynn TC, Carruthers JA, Caruthers J. Surgical pearl: the use of the Ultra-Fine II short needle 0.3 cc insulin syringe for botulinum toxin injections. J Am AcadDermatol. 2002;46(6):931-933. doi: 10.1067/mjd.2002.119202. [PubMed]

[11]. Carruthers JA, Caruthers J. Clinical indications and injection technique for the cosmetic use of BotulinumA exotoxin. Dermatol Surg. 1998;24:1189-1194. doi: 10.1016/S1076-0512(98)00189-7. [PubMed]

[12]. Matarosso SL. Complications of BotulinumA exotoxin for hyper functional lines. Dermatol Surg. 1998;24:1249-1254. doi: 10.1016/S1076-0512(98)00187-3. [PubMed]

[13]. Binder WJ, Blitzer A, Brinn MF. Treatment of hyper functional lines of the face with botulinum toxin A. Dermatol Surg. 1998;24:1198-1205. doi: 10.1016/S1076-0512(98)00181-2. [PubMed]

[14]. Matilde MS. New indications for botulinum toxin type-A in cosmetic: mouth and neck. PlastReconstr Surg. 2002;110:601-613. doi: 10.1097/00006534-200208000-00037. [PubMed]

[15]. Flynn TC, Carruthers JA, Carruthers JA. Botulinum A toxin treatment of the lower eyelid improves infraorbitalrhytides and widens the eye. Dermatol Surg. 2001;27:703-708. doi: 10.1046/j.1524-4725.2001.01038.x. [PubMed]

[16]. Goldman MP. Festoon formation after infraorbitalbotulinum toxin A: a case report. Dermatol Surg. 2003;29:560-561. doi: 10.1046/j.1524-4725.2003.29130.x. [PubMed]

[17]. Connor MS, Karlis V, Ghali GE. Management of the aging forehead: a review. Oral Surg Oral Med Oral Pathol Oral RadiolEndod. 2003;95:642-648. doi: 10.1067/moe.2003.240. [PubMed]

[18]. Pribtkin EA, Greco TM, Goode RI, Keane WM. Patient selection in the treatment of glabellar wrinkles with botulinum toxin type A injection. Arch Otolaryngol Head Neck Surg. 1997;123:321-326. doi: 10.1001/archotol.1997.01900030103013. [PubMed]

[19]. Fulton JE. Botulinum toxin: the Newport Beach experience. Dermatol Surg. 1998;24:1219-1224. doi: 10.1016/S10760512(98)00184-8. [PubMed]

[20]. Ahn K-Y, Park M-Y, Park D-H, Han D-G.Botulinum toxin A for the treatment of facial Hyperkinetic wrinkles in Koreans. PlastReconstr Surg. 2000;105:778-784. doi: 10.1097/00006534-200002000-00050. [PubMed]

[21]. Lew H, Yun YS, Lee SY, Kim SJ. Effect of botulinum toxin A on facial wrinkle lines in Koreans. Ophthalmologica. 2002;216:5054. doi: 10.1159/000048297. [PubMed]

[22]. Cather JC, Cather JC, Menter A. Update on botulinum toxin for facial esthetics. DermatolClin. 2002;20:749-761. doi: 10.1016/S0733-8635(02)00043-8. [PubMed]

[23]. Heckman M, Teichmann B, Schroeder U, Sprengelmeyer R, Ceballos-Baumann AO. Pharmacologic denervation of frown muscles enhances baseline expression of happiness and decreases baseline expression of anger, sadness, and fear. J Am AcadDermatol. 2003;49(2):213-216. doi: 10.1067/S0190-9622(03)00909-5. [PubMed]

[24]. Sadick N. Botulinum toxin type B for glabellar wrinkles: a prospective open label response study. Dermatol Surg. 2002;28(9):817821. doi: 10.1046/j.1524-4725.2002.02037.x. [PubMed]

[25]. Sadick N, Herman AR. Comparison of botulinum toxins A and B in the esthetic treatment of facial rhytides. Dermatol Surg. 2003;29:340-347. doi: 10.1046/j.1524-4725.2003.29082.x. [PubMed] 